\title{
Avaliação da qualidade das águas do Rio Belém, CuRITIBA-PR, COM O EMPREGO DE INDICADORES QUANTITATIVOS E PERCEPTIVOS
}

\section{Evaluation of Belem River water quality, Curitiba, PR, with the USE OF QUANTITATIVE AND PERCEPTIVE INDICATORS}

\section{RESUMO}

O objetivo principal deste trabalho foi avaliar o estado geral da qualidade das águas do rio Belém a partir de duas abordagens complementares: o uso do Índice de Qualidade das Águas da National Sanitation Foundation e de protocolos perceptivos (Indicador de Intensidade Antrópica e Indicador de Valor de Habitat). Para o monitoramento, foram selecionados 10 pontos no seu canal principal além da foz dos 13 tributários principais. Os resultados do IQA nsf mostraram perda progressiva da qualidade das águas da nascente para a foz em razão do aporte de esgotos domésticos oriundos das regiōes mais densamente habitadas próximas ao centro da cidade. A aplicação dos protocolos perceptivos mostrou maior variabilidade dos resultados, mas com tendência esperada em relação ao IQAnsf, indicando seu uso potencial como instrumento de avaliação complementar.
\end{abstract}

HARRY ALBERTO BOLLMANN

Doutor em Engenharia (Recursos hídricos e Saneamento Ambiental) pela Universidade Federal do Rio Grande do Sul. Professor do Curso de Graduação em Engenharia Ambiental e do Programa de Mestrado em Gestão Urbana da Pontifícia Universidade Católica do Paraná

\section{THIAGO EDWIGES}

Acadêmico do curso de graduação em Engenharia Ambiental da Pontifícia Universidade Católica do Paraná. Bolsista de Iniciação Científica do CNPq

Recebido: 17/01/08 Aceito: 11/11/08
PALAVRAS-CHAVE: Rio Belém, qualidade da água, percepção ambiental.

\begin{abstract}
The main purpose of this work was to evaluate the water quality of Belem River with two complementary strategies: the use of the National Sanitation Foundation Water Quality Index and the application of perceptive protocols (Human Intensity Index and Habitat Value Index). To access the water quality, 10 points at the main river channel as well as the estuary of its 13 main tributaries were selected. The WQInsf results showed a gradual loss of the water quality from the headwater to its mouth mainly due the presence of domestic effluents from the more densely populated areas located near the center of the city. The application of perceptive protocols showed more variable but predictable results indicating its potential as complementary methods of evaluation.
\end{abstract}

KEYWORDS: Belem River, water quality, environmental perception.

\section{INTRODUÇÃO}

A Bacia Hidrográfica do rio Belém é uma bacia genuinamente curitibana, historicamente constituindo-se como manancial superficial para diversos usos. Seu talvegue principal corta a cidade na direção norte-sul, atravessando pontos importantes como parques e áreas densamente povoadas como o centro da cidade. Com $84 \mathrm{~km}^{2}$, sua área de drenagem representa cerca de $20 \%$ da área do Município de Curitiba e abriga aproximadamente $50 \%$ de sua população. Engloba os principais bairros da cidade, entre eles o centro e os principais pontos notáveis naturais e arquitetônicos que tem representado a Cidade de Curitiba, conferindo-lhe uma grande importância simbólica, consideradas as dimensões geográfica, social, econômica e cultural. Por isso, a bacia do rio Belém é considerada de extrema importância para a cidade de Curitiba.

Entretanto, o estado de conservação das suas águas não está à altura da sua importância simbólica, estando poluídas e contaminadas, primordialmente, por esgotos domésticos e resíduos sólidos. Desde 1992, o Instituto Ambiental do Paraná realiza sistematicamente a avaliação da qualidade das suas águas em nove pontos amostrais situados em sua bacia hidrográfica. Os resultados mostram um rio classificado como "poluído" a "muito poluído” (IAP, 2005). Mesmo sem ter sido realizado qualquer levantamento ou estimativa sobre a poluição difusa, estima-se que cerca de $90 \%$ da poluição das águas do rio Belém é originária de esgotos domésticos, e $10 \%$ se origina a partir de efluentes industriais (SUDERHSA, 1998).

Os resultados do monitoramento obtidos neste trabalho permitirão avaliar, através da tendência central dos dados, as áreas com pior qualidade das águas e que representam as áreas prioritárias para a aplicação de medi- 
das de despoluição no âmbito da bacia hidrográfica do rio Belém. Além disso, espera-se estimular a busca de indicadores complementares de monitoramento de modo a ampliar a percepção da qualidade ambiental com baixo custo de monitoramento rotineiro.

\section{Monitoramento da qualidade das águas em rios urbanos}

A noção clássica de contaminação das águas, e de sua avaliação, envolve a determinação da presença e da concentração de substâncias potencialmente nocivas, baseada na identificação de poluentes específicos em pontos amostrais determinados, por meio de análises físicas, químicas e biológicas. Desconsidera-se, assim, o seu efeito nas comunidades aquáticas envolvidas, bem como a capacidade que os organismos vivos têm de atuar ativamente na manutenção do equilíbrio geral do ecossistema impactado.

Para contrapor a essa linha, alguns estudos puramente biológicos tentam identificar parâmetros que têm como objetivo monitorar a integridade das populações envolvidas, através da análise do efeito combinado dos vários processos potencialmente prejudiciais sobre um único indivíduo (bioindicador) ou sobre a estrutura das populaçōes. Segundo Hawkes (1979), o uso de indicadores biológicos para avaliar a qualidade das águas data do início do século na Europa com os trabalhos de Kolkwitz e Marsson entre 1908 e 1909, e pouco depois na América com os trabalhos de Richardson publicados em 1928. Mas só a partir dos resultados obtidos por Butcher, no mesmo ano, considerou-se seriamente a hipótese de usar organismos aquáticos como indicadores de poluição. Procurava-se então medir as conseqüências da poluição no equilíbrio das populações.

Esta mudança conceitual propiciou o desenvolvimento de critérios e padrōes de qualidade (ou da alteração da sua qualidade) baseados em características e indicadores biológicos do estado do ecossistema. Para USEPA (1993), em contraposição ao caráter específico e limitado das abordagens físicas e químicas, biocritérios são variáveis de resposta que tratam das conseqüências da poluição, integrando o efeito de múltiplos poluentes ou elementos alteradores no equilíbrio das populações, combinando múltiplas causas aos múltiplos efeitos observados nas comunidades aquáticas, sua organização ou fisiologia. Além disso, as respostas obtidas podem refletir, em maior ou menor grau, a habilidade adaptativa dos organismos presentes, bem como a resiliência da comunidade às perturbaçōes externas (pontuais ou difusas), permitindo acessar com maior abrangência a verdadeira significância ecológica das alteraçóes da qualidade da água. Porém, assim como a abordagem físico-química, esta aproximação também é limitada uma vez que as variáveis monitoradas apenas procuram representar os efeitos dos processos impactantes na biota local, e não refletem o estado geral do ecossistema entendido como composto por elementos bióticos e abióticos.

Uma avaliação criteriosa da qualidade das águas requer, portanto, uma estrutura metodológica que seja capaz de integrar variáveis representativas dos processos alteradores das suas condições estruturais, bem como das respostas à ação dos estímulos externos, que podem variar (em escala) do nível individual ao ecossistêmico. As abordagens baseadas em uma visão sistêmica da realidade têm procurado integrar aspectos físicos, químicos e biológicos, estabelecendo métodos de investigação que combinem variáveis de causa e efeito através de estruturas multimétricas (Barbour et al, 1995). Esta nova visão metodológica, longe de significar uma ruptura em relação aos processos tradicionais de monitoramento, procura integrar suas potencialidades. Utiliza, para isso, instrumentos matemáticos e estatísticos que possibilitem a agregação de informaçōes de naturezas diversas, de modo que, quando ponderadas conjuntamente, possam refletir o estado geral do ecossistema.

A idéia do uso de indicadores perceptivos para avaliar a qualidade das águas não é nova. $\mathrm{Na}$ verdade, os parâmetros organolépticos associados às águas de beber foram os primeiros argumentos de aceitação ou rejeição de um manancial. De uma forma ou de outra, até hoje continuam a desempenhar seu papel na avaliação da qualidade das águas.

Horton (Ott, 1978) propôs o primeiro indicador formal de qualidade das águas em 1965, agregando variáveis físicas e químicas quantitativas e termos incomensuráveis. Embora as variáveis selecionadas tivessem sido escolhidas do seu trabalho na Orsanco (Ohio River Water Sanitation Commission), sua formulação foi aplicada em mananciais de vários países no mundo. Originalmente, as variáveis quantitativas escolhidas foram: oxigênio dissolvido, potencial hidrogeniônico, coliformes, condutividade, carbono extraído por clorofórmio, alcalinidade, cloretos e a porcentagem da população servida com sistema de tratamento de esgotos. Adicionalmente, agregou dois coeficientes que refletiam a condição da temperatura (M1) e a existência de poluiçãao óbvia do manancial (M2). Este último termo, claramente qualitativo, reflete condições ofensivas observáveis no manancial, como a formação de depósitos de lodo, presença de óleos, detritos, espuma, materiais flutuantes e a descarga de despejos que contribuam para um excesso de cor e odor no manancial.

Apesar da pouca experimentação no Brasil, atualmente são previstos alguns critérios qualitativos (não numéricos) para a classificação das águas naturais na Resolução CONAMA No 357/05: (a) materiais flutuantes, inclusive espumas não naturais: virtualmente ausentes; (b) óleos e graxas: virtualmente ausentes; (c) substâncias que comuniquem gosto ou odor: virtualmente ausentes; (d) corantes provenientes de fontes antrópicas: virtualmente ausentes; (e) resíduos sólidos objetáveis: virtualmente ausentes (Brasil, 2005).

A Resolução CONAMA № 274/00 (Brasil, 2000), ao tratar dos critérios para recreação de contato primário, classifica as águas doces, salobras e salinas segundo o número mais provável de coliformes fecais (termotolerantes), Escherichia coli ou enterococos, em três categorias de qualidade: excelente, muito boa e satisfatória. A mesma avaliação considera como imprópria para o contato primário as águas que apresentem, entre outros critérios, presença de resíduos ou despejos, sólidos ou líquidos, inclusive esgotos sanitários, óleos, graxas e outras substâncias, capazes de oferecer riscos à saúde ou tornar desagradável a recreação. Tratam-se, portanto, de critérios perceptivos, cujo monitoramento não importa necessariamente em gastos adicionais.

Mesmo assim, a maioria dos procedimentos de classificação das águas para fins de enquadramento segundo as resoluçōes CONAMA № 357/05 e 
No 274/00 fundamenta-se em critérios quantitativos, colocando-os como variáveis exclusivas ou quando muito como prioritárias em relação às perceptivas. Não se trata de deixar de reconhecer a importância dos critérios numéricos das variáveis quantitativas, mas de considerar a complementaridade das informações perceptivas para o monitoramento. Apesar da oportunidade do uso de variáveis qualitativas, no território brasileiro são praticamente inexistentes os programas de monitoramento que procuram sistematicamente observar tais critérios e associá-los com variáveis quantitativas. Esta lacuna deve-se, em grande parte, à falta de informação sobre os procedimentos de construção de escalas qualitativas que permitam sua referenciação, e o desconhecimento da utilidade prática dos seus resultados.

Karr e Chu (1999) incentivam o uso de indicadores perceptivos de atividade antrópica para associá-los com elementos da qualidade das águas. Rossano (1995) apud Karr e Chu,
(1999) analisou os resultados da aplicação do IBI - B (Índice de Integridade Biótica aplicado a Macroinvertebrados Bentônicos) em 115 mananciais no Japão, bem como o grau de atividade e influência humana observados nas correspondentes bacias hidrográficas. Mesmo sem nenhuma medida quantitativa, o método prevê um índice variando de 1 a 21 para a intensidade da influência humana, baseado em quatro critérios estabelecidos como ilustrado na Figura 1.

A Figura 2 apresenta a relação da intensidade da influência humana com o IBI-B. Percebe-se a clara relação encontrada no estudo entre uma medida quantitativa (IBI-B) e uma variável não quantificável (influência humana), a qual foi apenas avaliada, não quantificada. A associação demonstra a validade do uso da variável qualitativa.

Barbour e Stribling (1996) apresentam uma técnica de avaliação do habitat de rios admitindo as métricas apresentadas na Tabela 1. A metodolo- gia foi adotada como referência para a classificação dos mananciais americanos (USEPA, 1996).

O Programa de Monitoramento dos Rios de Maryland (EUA) é caracterizado pelo uso de diversas métricas e tipos de indicadores, os quais são comumente associados entre si. Dentre os indicadores perceptivos mais usados, o indicador de Valor de Habitat apresentado na Tabela 1 tem sido regularmente associado com o Índice de Integridade Biológica aplicado a peixes (Figura 3). Percebe-se nessa figura uma relação direta entre os valores obtidos pelo protocolo perceptivo e a integridade biológica das comunidades de peixes.

Wilhem e Dorris (1968) e James (1978) já há mais de 30 anos demonstraram que os aspectos físicos, químicos e biológicos são diferenciados, mas profundamente interconectados. Alterações em um aspecto produzem efeitos nos outros. Por esta razão, esses autores indicam que os métodos de avaliação devem ser complementares, e

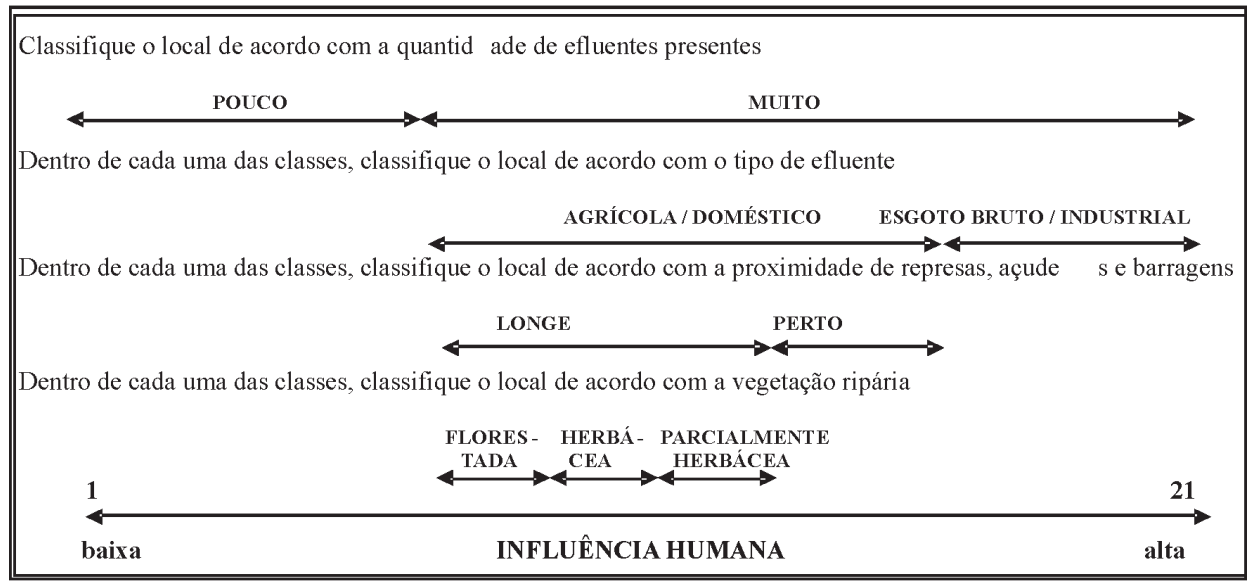

Fonte: Rossano (1995) apud Karr e Chu (1999)

Figura I - Instrumento de avaliação do índice de atividade antrópica

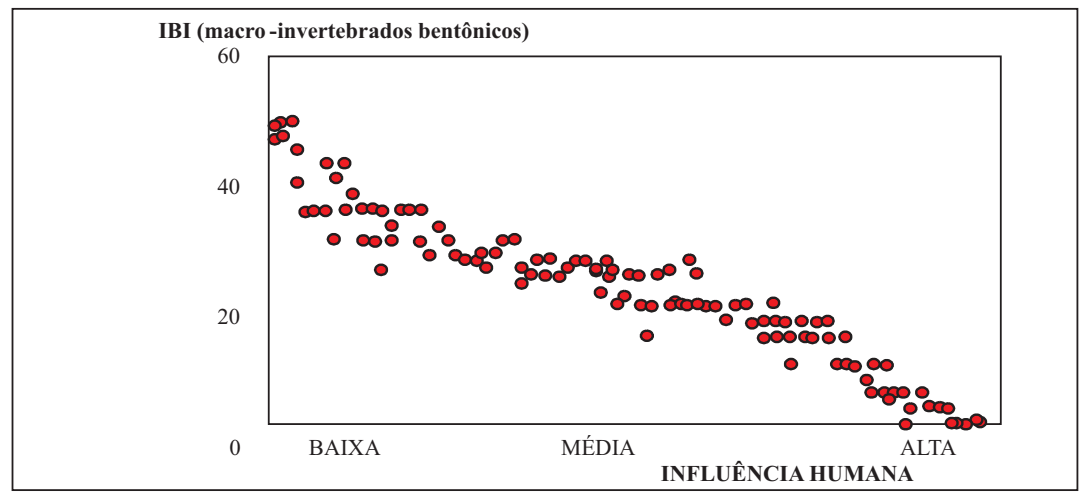

Fonte: Rossano (1995) apud Karr e Chu (1999)

Figura 2 - Índices de integridade biológica de macroinvertebrados bentônicos em I I5 rios japoneses conforme o grau de influência humana 
Tabela I - Métricas para a avaliação visual do habitat em rios

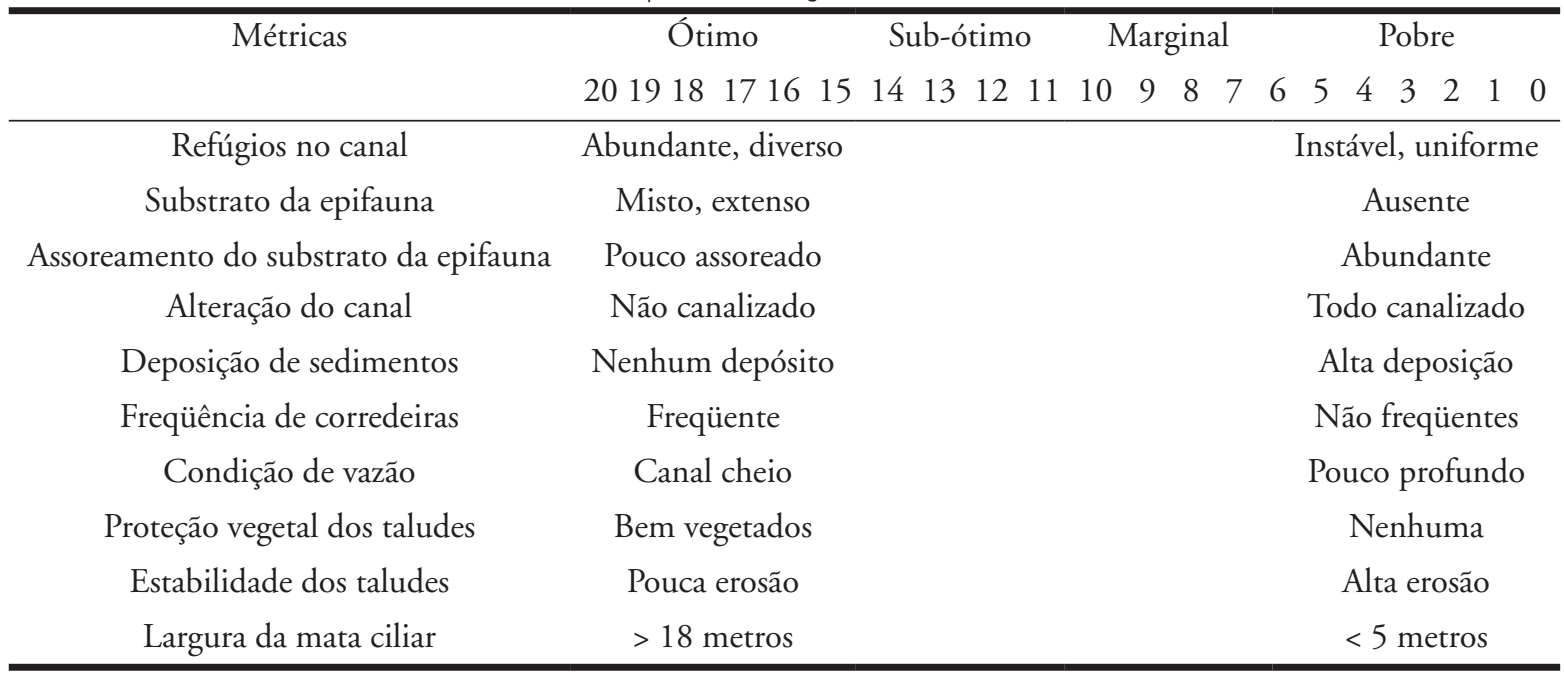

Fonte: Barbour e Stribling (1996)

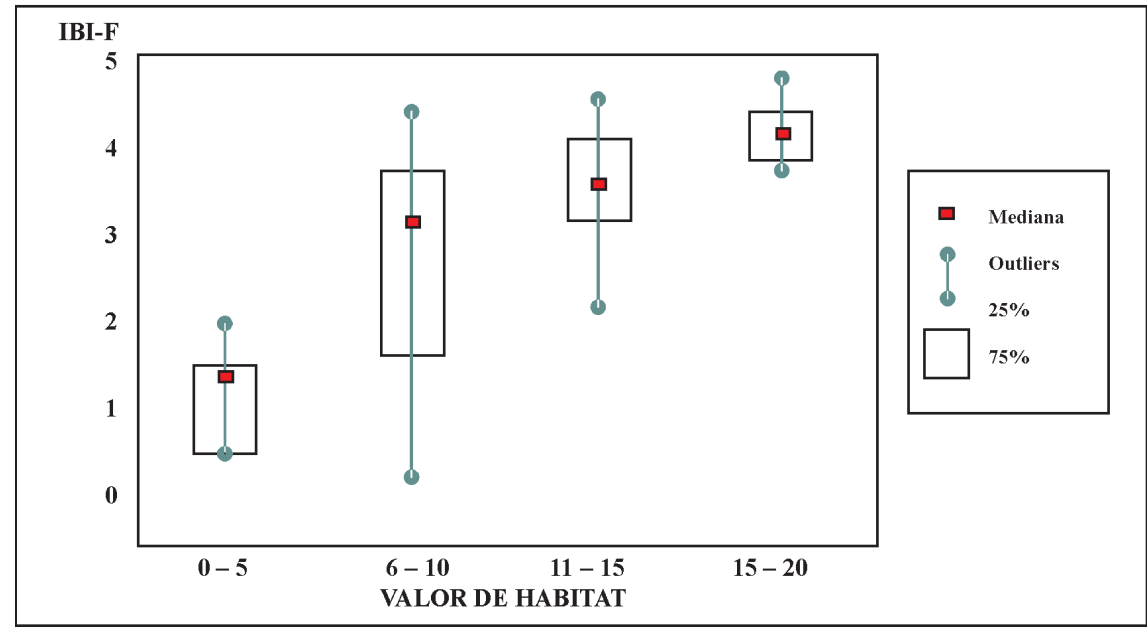

Fonte: Usepa (1996)

Figura 3 - Associação entre valor do habitat e índice de integridade biológica de peixes

usados de forma integrada. Um esforço interessante e largamente empregado para avaliar a qualidade das águas naturais é o exemplo da estruturação do Índice de Qualidade das Águas, elaborado pela National Sanitation Foundation na década de 70 (IQAnsf). Originalmente esse indicador foi concebido para avaliar a qualidade geral das águas dos rios não poluídos (Ott, 1978). Conceitualmente, é um número resultante de uma síntese de valores e pesos atribuídos à vários parâmetros físicos, químicos e bacteriológicos, e fornece uma indicação relativa da qualidade da água em diferentes pontos no espaço ou tempo (ISAM, 1999). A criação desse indicador baseou-se numa pesquisa de opinião junto a especialistas em qualidade das águas que indicaram os parâmetros a serem avaliados, o peso relativo dos mesmos e a condição com que se apresenta cada parâmetro, segundo uma escala de valores. Dos 35 parâmetros indicadores inicialmente propostos, somente nove foram selecionados: temperatura, potencial hidrogeniônico $(\mathrm{pH})$, demanda bioquímica de oxigênio (DBO), nitrogênio total, oxigênio dissolvido, sólidos totais, fósforo total, turbidez, coliformes fecais (termotolerantes). O IQAnsf é calculado pelo produto ponderado de valores de qualidade correspondentes aos parâmetros considerados, por meio da seguinte fórmula:

IQAnsf $={ }_{i=1}^{\mathrm{n}} \mathrm{P}$ qi ${ }^{\mathrm{wi}}$

Onde:

IQAnsf: valor índice representativo da qualidade da água (entre 0 e 100); qi: qualidade do i-ésimo parâmetro obtido em função da sua concentração ou medida (entre 0 e 100);

wi: peso correspondente ao i-ésimo parâmetro, atribuído em função de sua importância para a conformação global de qualidade (entre 0 e 1 );

n: número de parâmetros que entram no cálculo do IQAnsf.

A partir do cálculo efetuado, pode-se atribuir valor à qualidade das águas naturais, indicada pelo IQAnsf numa escala de 0 a 100 , avaliando-a desde o ponto de vista de sua tratabilidade para abastecimento e consumo humano (Tabela 2).

Apesar de se reconhecer que é necessária uma avaliação integrada (física, química e biológica) para minimizar as incertezas relativas à avaliação da qualidade das águas, principalmente em rios urbanos, a legislação brasileira 
Tabela 2 - Escala de indicação da qualidade das águas naturais para o IQAnsf

\begin{tabular}{cc}
\hline Categoria & Ponderação \\
\hline Ótima & $79<$ IQAnsf $\leq 100$ \\
Boa & $51<$ IQAnsf $\leq 79$ \\
Aceitável & $36<$ IQAnsf $\leq 51$ \\
Imprópria para tratamento convencional & $19<$ IQAnsf $\leq 36$ \\
Imprópria para qualquer tipo de uso & $0<$ IQAnsf $\leq 19$ \\
\hline
\end{tabular}

Fonte: Cetesb (2008)

apresenta-se baseada quase exclusivamente em aspectos físicos e químicos, com poucos elementos de consideração dos aspectos biológicos e perceptivos $\mathrm{da}$ qualidade; reconhece, entretanto, sua aplicação complementar. Neste trabalho, procurar-se-á associar protocolos perceptivos aos tradicionais (físicos, químicos e bacteriológicos) para avaliar a qualidade das águas do rio Belém.

\section{METODOLOGIA}

Esta pesquisa foi estruturada em três fases distintas e complementares: fase exploratória, fase descritiva e fase analítica. $\mathrm{Na}$ fase exploratória, procurou-se conhecer os procedimentos normalmente utilizados para o monitoramento da qualidade das águas em bacias hidrográficas urbanas. A pesquisa das fontes de informação foi efetuada com base no Método da Problematização (Santos, 2004). Após o levantamento das necessidades específicas, as variáveis mais adequadas para compor o Plano Amostral foram identificadas através de busca em fontes de informação congêneres, bem como através da análise dos dados já existentes sobre a qualidade das águas.

Uma vez identificadas as variáveis de monitoramento, foram selecionados os pontos amostrais (densidade amostral da bacia) a partir do levantamento em mapas hidrográficos da bacia (Figura 4).

Os critérios básicos que fundamentaram a escolha dos pontos amostrais basearam-se nas seguintes considerações:

a) Foram mantidos os pontos já monitorados na bacia hidrográfica do rio Belém;

b) Foram levantados, a partir de mapas hidrográficos todos os prováveis afluentes do rio Belém. Porém, em visitas a campo, constatou-se que nem todos os tributários representados nos mapas obtidos são efetivamente corpos hídricos reais da bacia.

c) Existem além desses, trechos secos, canais fechados e inúmeros pontos de lançamento de águas pluviais. A partir dessas visitas foram então selecionados, somente os afluentes ao canal principal do rio Belém em canais abertos, os quais foram denominados Tributários Principais.

Do ponto de vista geográfico, a bacia do rio Belém foi subdividida em três trechos. O primeiro trecho corresponde os pontos RB1, RB3, RB4, RB5 e RB6, e representa a região norte da Bacia Hidrográfica. Nela, o rio ainda corre, em sua maior parte, em seu leito natural. Compreende a região das nascentes, na

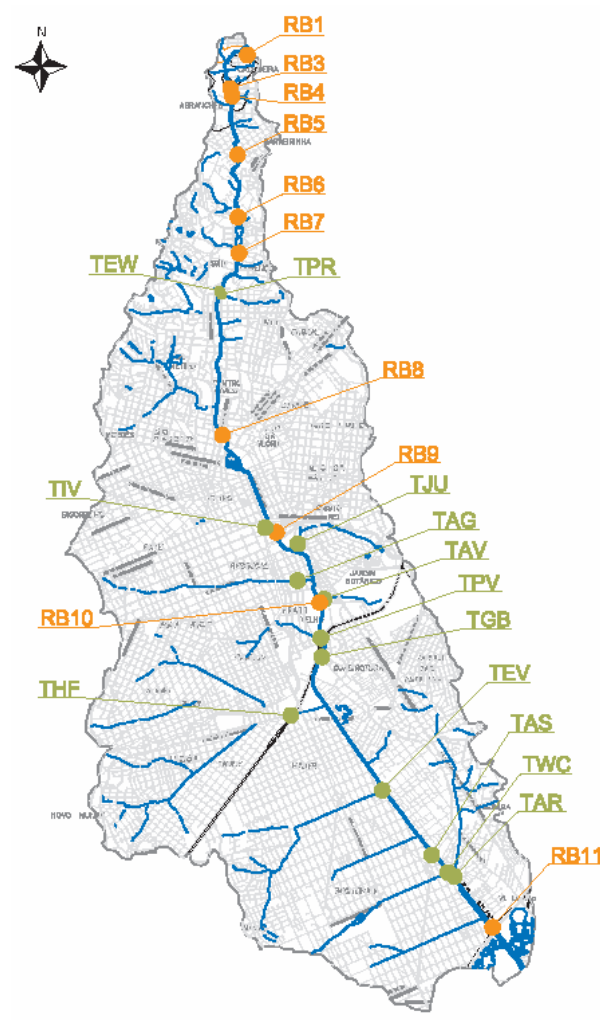

PONTOS AMOSTRAIS

RB1 - Nascente principal

RB3 - Montante de ocupação irregular

RB4 - Montante Vila Diana

RB5 - Jusante Vila Diana

RB6 - Entrada Lago Pq. São Lourenço

RB7 - Saída Lago Pq São Lourenço

TEW - Tributário Evaldo Wendler

TPR - Tributário Primavera

RB8 - Rua Cândido de Abreu

RB9 - Estação Rodoferroviária

TIV - Tributário Ivo

TJU - Tributário Juvevê

TAG - Tributário Água Verde

TAV - Tributário Aviário

RB10 - PUCPR

TPV - Tributário Prado Velho

TGB - Tributário Guabirotuba

THF - Tributário Henry Ford

TEV - Tributário Evaristo da Veiga

TAS - Tributário Antonio Schiebel

TWC - Tributário Waldemar de Campos

TAR - Tributário Areiãozinho

RB11 - Foz do Rio Belém

Figura 4 - Representação dos pontos amostrais no rio Belém e tributários principais 
ciliar do rio Belém, com lançamento de esgotos diretamente nas suas águas. Esses moradores já receberam intimação para desocupação da área há pelo menos três anos, mas com são moradores que ali permanecem há pelo menos 15 anos, aguardam o processo de realocação por parte da municipalidade. O ponto RB5 situa-se após a Vila Diana, que é uma ocupação urbana de média densidade populacional (entre 50 a $100 \mathrm{hab} / \mathrm{ha}$ ), mas ainda com problemas de ligaçōes clandestinas de esgotos sanitários à rede pluvial. O ponto RB6 representa a entrada do Parque São Lourenço, onde o rio deságua no lago do parque.

O segundo trecho corresponde à região central da cidade de Curitiba, que apresenta os bairros com o maior nível sócio-econômico da população urbana de Curitiba, e compreende os pontos RB7, RB8 e RB9. O ponto RB7 está situado na saída do lago do Parque São Lourenço, alvo de obras de dragagem dos sedimentos e do lodo de fundo durante o período do monitoramento. Entre os pontos RB7 e RB8 o rio corre em canal aberto por área urbana consolidada que apresenta atividade residencial e comercial, principalmente de restaurantes e de serviços. Entre os pontos RB8 e RB9, o rio Belém percorre cerca de $2 \mathrm{~km}$ em canal fechado. Esta é a região de maior densidade populacional, caracterizada pelo centro da cidade de Curitiba, e onde a urbanização se consolidou sobre sua caixa. No ponto RB9, o rio volta a ser contido em um canal aberto semiretificado até o ponto RB10.

O terceiro trecho corresponde novamente a bairros periféricos do centro urbano, com um padrão sócioeconômico que cai progressivamente, a partir do centro até a região da foz do rio Belém. O canal principal do rio é caracterizado por longo trecho retificado, para minimizar os problemas de alagamentos provocados pelas cheias do rio e permitir maior ocupação do solo urbano na região. Os pontos amostrais desse trecho são os pontos RB10, situado dentro do campus da PUCPR, e o ponto RB11, situado próximo à foz do rio Belém. Observa-se que dentro do campus da PUCPR, o rio percorre aproximadamente $1 \mathrm{~km} \mathrm{e}$, nesse percurso, sua mata ciliar ainda está preservada. Aliás, este é o único trecho significativo do rio Belém, em toda sua extensão, que apresenta vegetação ciliar preservada. Nas proximidades do ponto RB10, e à montante deste, deságuam os três tributários com maior potencial de poluição das águas do rio Belém: rios Ivo, Juvevê e Âgua Verde, os quais drenam as regiōes centrais mais densamente habitadas da cidade de Curitiba e apresentaram as maiores concentrações de poluentes detectadas no monitoramento.

Considerando os pontos amostrais selecionados dentro da unidade de planejamento adotada para este estudo, elaborou-se um plano amostral baseado na coleta mensal de amostras com a finalidade de avaliar a qualidade das águas por meio do IQAnsf. Os materiais (equipamentos, frascos e garrafas coletoras), os procedimentos de coleta, preservação, acondicionamento, transporte, bem como as determinações físicas, químicas e biológicas foram efetuados com base no Standard Methods for the Examination of Water and Wastewater (APHA, AWWA, WEF, 1999) As análises foram realizadas no Laboratório de Análises Ambientais da PUCPR. Foram realizados dez campanhas mensais de coleta de amostras no período de fevereiro a novembro de 2007 , e a partir do resultado de cada esforço amostral, foram calculados os valores do IQAnsf.de cada amostra, bem como a mediana dos valores do IQAnsf em cada ponto.

Complementarmente, foram aplicados dois protocolos perceptivos nos pontos do canal principal do rio Belém: o indicador de Valor de Habitat (Barbour et al, 1999), que avalia perceptivamente as condiçôes dos cursos d'água, tais como variabilidade de fundo, alteração do canal, bem como a situação das suas margens, avaliando a proteção e estabilidade das mesmas e existência de mata ciliar, e o Índice de Influência Antrópica, estabelecido por Karr e Chu (1999) e que prevê, sem nenhuma medida quantitativa, um índice variando de 1 a 24 para a intensidade de influência humana nas regiōes circunvizinhas aos cursos d'água. Esses indicadores, apesar de perceptivos e de terem certo grau de subjetividade na sua aplicação, são elementos importantes a serem associados aos resultados do IQAnsf, principalmente para fins de educação ambiental uma vez que não dependem de complexas e caras rotinas laboratoriais para a obtenção dos resultados.

\section{RESULTADOS E DISCUSSÃO}

\section{Protocolos perceptivos aplicados aos pontos amostrais no canal principal do Rio Belém}

$\mathrm{Na}$ Figura 5 apresentam-se os Valores de Habitat atribuídos aos diversos pontos de amostragem, de acordo com a metodologia proposta por Barbour et al (1999). O Indicador de Valor de Habitat (IVH) representa claramente como o uso e a ocupação do solo refletem-se na condição do ambiente próximo ao curso d'água, visto que o maior valor foi obtido no ponto RB1 - Nascente do rio Belém, que se situa dentro do Parque das Nascentes e onde não há ocupação urbana próxima. Nos pontos RB3, RB4 e RB5, o IVH assume valores progressivamente menores, refletindo condições de urbanização crescente, cada vez mais densa, e com menor proteção ciliar do canal principal do rio Belém. No ponto RB6 o IVH volta a aumentar, em razão desse ponto estar situado no limite do Parque São Lourenço, em uma região de moradias de alto padrão e menor densificação urbana. Os pontos RB7 e RB8 são os mais próximos à zona central da cidade e, assim, a alta densidade de ocupação urbana é refletida nos baixos escores obtidos. Do ponto RB7 ao ponto RB11, os valores do IVH tendem a aumentar em razão do seu afastamento da região central de Curitiba e de sua localização (RB9 dentro da Estação Rodoferroviária de Curitiba; RB10 dentro do Campus da PUCPR e RB11 dentro do Parque do Iguaçu próximo à foz do rio Belém), sem, entretanto, alcançar o valor máximo observado $(11,1$ no ponto RB1). Em geral, esse exercício indica perda no valor de habitat do canal principal do rio Belém situado na região sul da bacia comparando-se com a região das nascentes.

$\mathrm{Na}$ Figura 6 apresentam-se os valores do Îndice de Influência Antrópica (IIA) atribuídos aos diversos pontos de amostragem, de acordo com a metodologia proposta por Karr e Chu (1999).

O valor do IIA no ponto RB1 reflete a menor influência humana, em função de sua localização dentro do Parque das Nascentes. De forma similar, os pontos RB4 e RB7 também receberam valores de IIA relativamente baixos em 


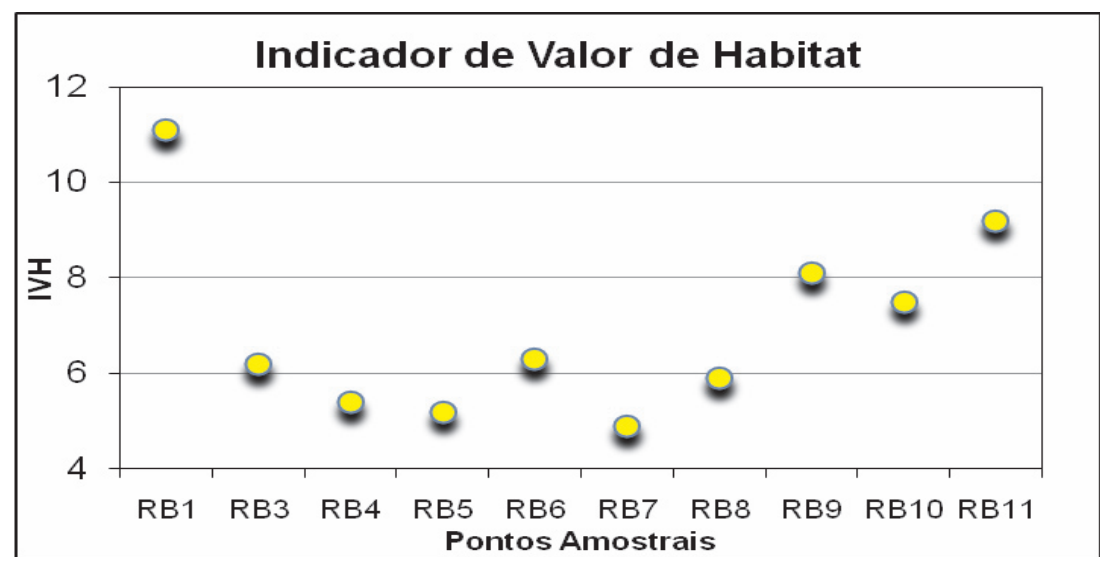

Figura 5 - Variação do Índice de Valor de Habitat ao longo do canal principal do rio Belém

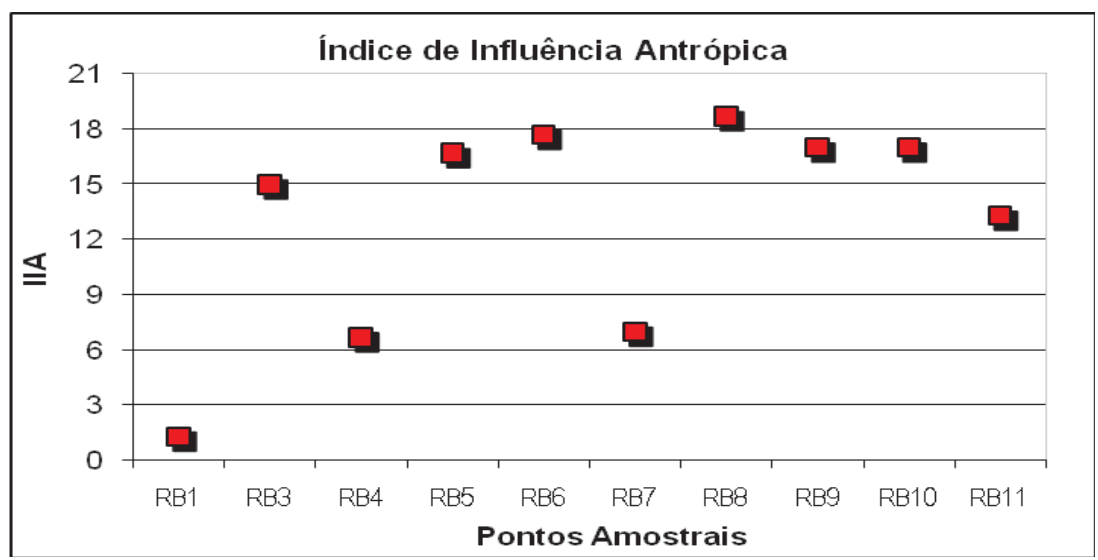

Figura 6 - Variação do Índice de Influência Antrópica ao longo do canal principal do rio Belém

função de características locais como a proteção por matas ciliares.

As ocupações irregulares das matas ciliares por moradias junto ao ponto RB3, a ocupação urbana da Vila Diana (ponto RB5) e a existência de urbanização consolidada próxima ao Parque São Lourenço (ponto RB6), foram fatores determinantes para a caracterização de alta influência antrópica nesses pontos. Os valores obtidos a partir do ponto RB8 refletem a alta taxa de urbanização da região central da cidade de Curitiba e como os impactos negativos causados pela população se estendem até a foz do rio Belém, embora de maneira decrescente.

\section{Índice de qualidade da água obtidos em pontos do canal principal do Rio Belém e na foz dos tributários principais}

A Figura 7 apresenta a variação do IQAnsf para os 10 pontos amostrais constatar que o rio Belém mantém seu estado de poluição, mostrando que neste curto espaço os mecanismos de autodepuração das águas não foram efetivos na recuperação da qualidade da água. O IQAnsf no ponto RB6 (saída do lago do parque São Lourenço) foi, em termos medianos, pior do que o do ponto RB7 (entrada no parque), em razão das obras de dragagem dos sedimentos e do lodo de fundo do lago, realizadas no período do monitoramento. Algumas variáveis como cor, turbidez e sólidos suspensos totais aumentaram acentuadamente do ponto RB6 para o RB7 em função do revolvimento do material bentônico durante a dragagem realizada no lago.

As contribuiçôes localizadas entre os pontos RB7 e RB8 foram capazes de alterar a qualidade das águas neste trecho, passando de imprópria para o tratamento convencional a aceitável. Os córregos Primavera (TPR) e Ewaldo Wendler (TEW), localizados entre esses dois pontos, podem ter proporcionado efeito de diluição das águas do rio Belém melhorando assim sua qualidade. Além disso, a existência de infraestrutura de saneamento básico de melhor qualidade e o fato de, nesse trecho, o rio estar confinado em canal concretado aberto podem ter contribuído para a melhora da qualidade da água. Considera-se que, em canais abertos, as ligaçôes clandestinas de esgotos domésticos são prontamente identificadas e facilitam o trabalho fiscalizatório por parte da companhia de saneamento.

No ponto RB8 as águas do rio Belém entram em um canal fechado e voltam a aflorar no ponto RB9. Ao contrário do trecho anterior, em um canal fechado não se pode identificar facilmente as ligaçôes clandestinas de esgotos domésticos, comerciais ou até mesmo industriais na rede pluvial. Os impactos nesse trecho proporcionaram redução do IQAnsf em aproximadamente 30 pontos, chegando ao ponto RB9 com qualidade imprópria para qualquer tipo de uso.

Entre os pontos RB9 e RB10 do canal principal do rio Belém deságuam os rios Ivo (TIV), Água Verde (TAG) e Juvevê (TJU), que apresentaram as maiores concentrações de poluentes ao longo de todos os pontos monitorados. Essa elevada concentração de poluentes e a qualidade das águas que chegam do ponto RB9 foram, certamente, fatores contribuintes para a classificação das águas do ponto RB10 como imprópria 
para qualquer tipo de uso. Isso se faz sentir a jusante e o rio chega à sua foz com qualidade ainda imprópria para qualquer tipo de uso (ponto RB11).

Os índices medianos do IQAnsf obtidos para os 13 tributários do canal principal do rio Belém estão apresentados na Figura 8. Os tributários monitorados apresentaram, em geral, baixos valores, atingindo no máximo 40 dos 100 pontos na escala do IQAnsf. Apenas os tributários mais próximos às nascentes (córregos Primavera - TPV, e Ewaldo Wendler - TEW), localizados no terço inicial da bacia, apresentaram condição aceitável de qualidade das águas.

Os córregos que drenam a região central da bacia do rio Belém, e onde a densificação urbana é a mais intensa, foram os que apresentaram pior qualidade das águas (rios Ivo - TIV, Água Verde - TAG, Juvevê - TJU, Guabirotuba - TGB e Henry Ford - THF). Por fim, os córregos que drenam o terço final da bacia hidrográfica apresentaram uma qualidade intermediária entre os trechos inicial e central, mas ainda considerados Impróprios para o Tratamento Convencional das águas. Nesta região, a densificação urbana não é tão intensa quanto a observada na região central, mas é nitidamente maior do que aquela existente na porção inicial da bacia.

\section{Associação entre o IQAnsf e os protocolos perceptivos}

A Figura 9 ilustra a tentativa de associação entre os protocolos perceptivos e o IQAnsf. Tratam-se de grandezas que representam diferentes visôes sobre a qualidade local do corpo d'água avaliado. Enquanto o IQAnsf avalia exclusivamente a qualidade das águas, sem se preocupar com a estrutura física do curso d'água, o IVH avalia se o corpo d'água apresenta uma estrutura física adequada para a colonização pelas comunidades aquáticas, sem se preocupar diretamente com a qualidade das águas.

De forma análoga, o IIA procura avaliar as condiçốes de ocupação da região próxima ao corpo d'água, usando uma lógica baseada no fato de que quanto mais intensa e próxima é a presença humana, maiores os efeitos dos resíduos das suas atividades no corpo hídrico. São, portanto, avaliações complementares, mas não necessariamente convergentes nos seus resultados.

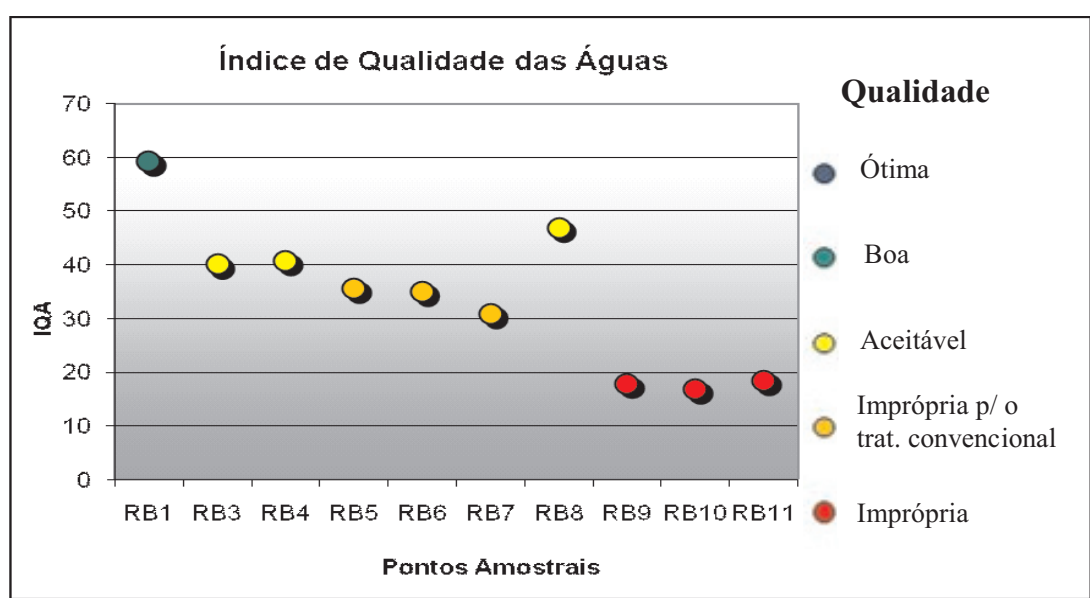

Figura 7 - Variação do IQAnsf ao longo do rio Belém

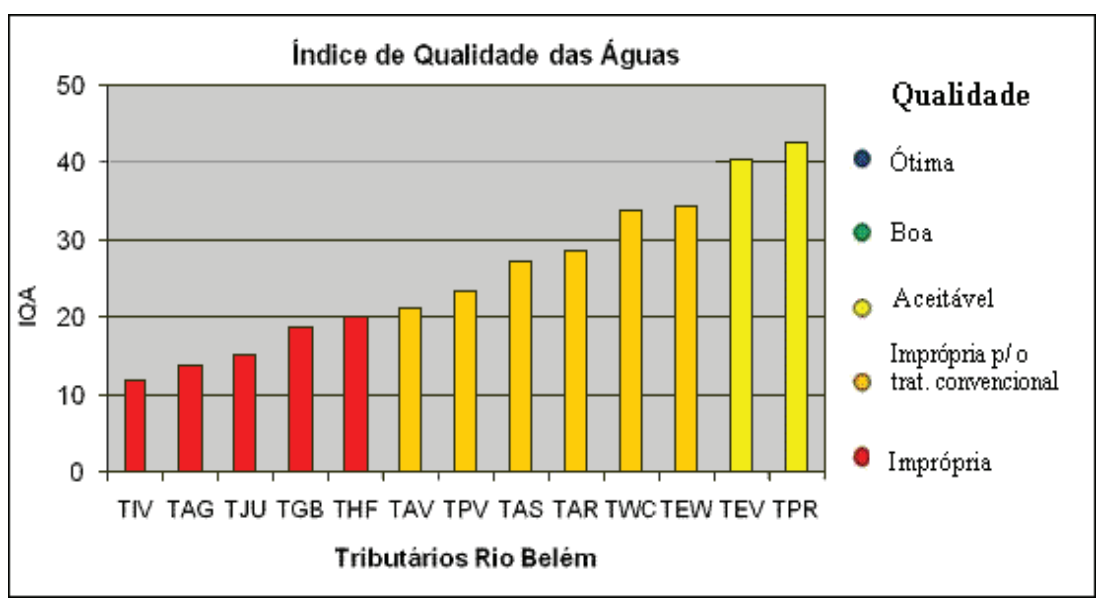

Figura 8 - IQAnsf medianos obtidos para os tributários principais do rio Belém

Em relação ao IVH, teoricamente, quanto maior o escore obtido para esse indicador, melhor é a condição da estrutura física do canal do rio para receber as comunidades aquáticas. Como nessa avaliação estão envolvidas variáveis como o grau de proteção das margens e a estrutura da mata ciliar, quanto melhor a condição destes elementos, maior a proteção do corpo d'água contra os fatores que contribuem para a sua poluição. Como resultado, deveriam ser alcançadas maiores notas do IQAnsf. Entretanto, esta relação não se apresentou assim tão direta para o rio Belém, onde foram encontrados valores intermediários de Valor de Habitat (entre 7 e 11) tanto para locais com boa qualidade das águas (IQAnsf = 60) quanto para locais com a pior qualidade (IQAnsf menor que 20).

Os pontos amostrais RB9, RB10 e RB11, de pior qualidade das águas, foram os de pior correspondência com o IVH. Já o grupo formado pelos pontos RB3, RB4, RB5, RB6, RB7 e RB8 (que apresentaram valores médios de IQAnsf e IVH e correspondem ao trecho parcialmente preservado e com características naturais), bem como o ponto RB1 (que representa as melhores condiçōes de estrutura física e de qualidade das águas), apresentaram melhor associação (Figura 9).

A associação entre o IIA e o IQAnsf foi ainda menos visível, provavelmente em função da maior variabilidade do IIA (Figura 6). Entretanto, em linhas gerais, a tendência é a esperada: pior qualidade das águas (menores valores de IQAnsf) nos pontos com maiores valores de intensidade de ocupação antrópica.

\section{CONCLUSÕES}

Apesar de ter sido originalmente concebido para avaliar a qualidade das 
águas de rios não poluídos, e posteriormente aplicado para avaliação da tratabilidade da água para consumo humano, no escopo deste trabalho o IQAnsf mostrou como bom indicador da qualidade geral de um rio urbano poluído (Rio Belém), expressando adequadamente a perda progressiva de qualidade a partir das nascentes em direção à sua foz. A correspondente diminuição dos valores do IQAnsf espelha o efeito conjunto de fontes pontuais e difusas de poluição, como por exemplo, o crescente acúmulo de matéria carbonácea oriunda de esgotos domésticos lançados no rio e seus tributários, e o aumento da área de drenagem contribuinte ao ponto de monitoramento. As variáveis componentes da sua estrutura, principalmente a DBO, Nitrogênio, Fósforo, Coliformes Fecais, Turbidez, Sólidos Totais, são características de despejos orgânicos comumente lançados em rios urbanos. Sua concentração nos corpos d'água receptores são também proporcionais à quantidade de esgotos domésticos pouco ou não tratados lançados nos rios. Desse modo, mesmo que os resultados numéricos do IQA possam sofrer alguma contestação, o seu uso como indicador relativo propiciou a comparação do grau de poluição entre pontos amostrais com bons resultados.

De modo complementar, os indicadores perceptivos refletiram a situação da condição da estrutura física do rio (IVH) e a situação da ocupação antrópica na região circunvizinha ao ponto amostral (IIA). Os indicadores perceptivos mostraram-se adequados para descrever as variações da condição de uso e ocupação do solo na bacia do rio Belém, com piores resultados obtidos nas regióes de maior atividade antropogênica próximas ao centro da bacia e, em contrapartida, melhores resultados nas regiōes de melhor condição ambiental próximas à região das nascentes e da sua foz.

Conclui-se que os indicadores utilizados neste trabalho fornecem informaçôes distintas e complementares na avaliação do estado ambiental e da qualidade da água de recursos hídricos, contribuindo para ampliar o entendimento das transformações ocorridas na qualidade das águas superficiais do Rio Belém.

Por fim, os resultados indicaram que a região central da bacia do Rio Belém (Rios Ivo, Juvevê e Água Verde),

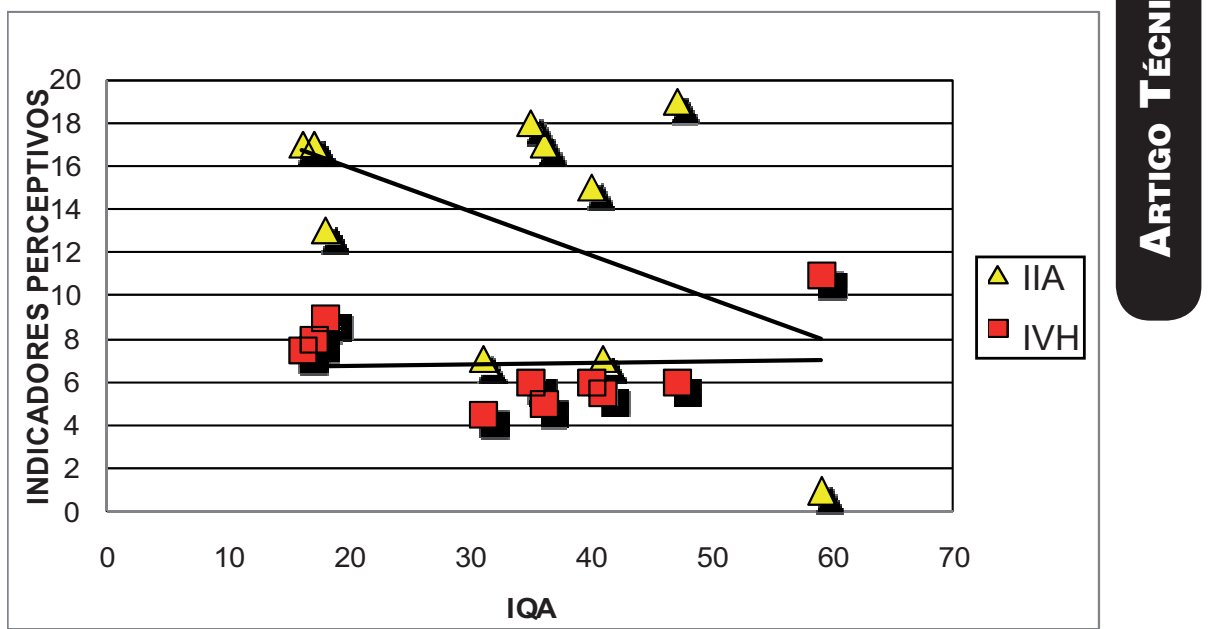

Figura 9 - Relação entre a qualidade das águas do rio Belém medida pelo Índice de Qualidade das Águas (IQAnsf) e os resultados da aplicação de indicadores perceptivos de Intensidade Antrópica (IIA) e de Valor de Habitat (IVH)

pelos piores resultados apresentados na aplicação dos indicadores estudados, representa a área prioritária de investimentos na despoluição do Rio Belém.

\section{AGRADECIMENTO}

Ao CNPq pelo financiamento concedido ao projeto por meio do Edital CTHIDRO 05/2006: projeto 500119/2006-6, e a PUCPR pelas bolsas de Iniciação Científica complementares.

\section{REFERÊNCIAS}

APHA, AWWA, WEF. Standard methods for the examination of water and wastewater. $21 \mathrm{ed}$. American Public Health Association, American Water Works Association, Water Environment Federation. 1009p.; Washington D.C, 1999.

BARBOUR, M.T.; STRIBLING, J.B. A workshop on a technique for assessing stream habitat structure for nonpoint source evaluation. In: Anais do Watershed 96', S 57 01/665-670. Disponível em: http://www.epa.gov/owow. Acesso em 23/11/1999.

BARBOUR, M.T.; STRIBLING, J.B. e KARR, J.R. Rapid bioassessment protocol for use in streams and wadable rivers. Environmental Protection Agency, EPA 841-B-99-002. Washington D.C, 1999, 339p. Disponível em: http://www.epa.gov/ owow/monitoring. Acesso em: [15/10/2006].

BRASIL. Resolução CONAMA 274 de 29 de Novembro de 2000. Disponível em http://www. $\mathrm{mma}$.gov.br/port/conama/res/res00/res 27400 . $\mathrm{html}$. Acesso em [15/02/2008].

BRASIL. Resolução CONAMA 357 de 17 de março de 2005. Disponível em http://www.mma.gov. $\mathrm{br} /$ port/conama/res/res05/res35705.html. Acesso em [15/02/2008].

CETESB. Indice de qualidade das águas. Disponível em http://www.cetesb.sp.gov.br. Acesso em 20/02/2008
CROMBIE, D. e DOERING, R.L. An ecosystem approach to the regeneration of cities. Rev. Ecodecision, New York, USA, p.(57-59). December 1991.

HAWKES, H.A. Invertebrates as indicators of river water quality. In: Biological Indicators of Water Quality (James, A. e Evison, L. Editores). John Willey and Sons Ltda., Great Britain, p(2-1 a 2-45); 1979.

IAP. Monitoramento da qualidade das águas na região metropolitana de Curitiba. Instituto Ambiental do Paraná. Curitiba, 1995.

ISAM. IQAnsf: Indice de qualidade das águas. Manual do software IQA 5.0. Pontifícia Universidade Católica do Paraná, Curitiba, 30 p. 1999.

JAMES, A. The value of biological indicators in relation to other parameters of water quality. In: Biological Indicators of Water Quality (JAMES, A e EVISON, L. - organizadores). John Wiley \& Sons Ltda. Great Britain, p(1-16). 1978.

KARR, J.R.; CHU, E.W. Restoring life in running waters: better biological monitoring. Island Press Ed., Washington DC, 206p. 1999.

OTT, W.R. Environmental indices: theory and practice. Ann Arbor Science Pub. Inc., Ann Arbor/MICH(EUA), 371p. 1978.

SANTOS, R.F. Planejamento ambiental: teoria e prática. São Paulo: Oficina de Textos, 184p. 2004.

SPIEGEL, M.R. Estatística. 3 Ed., Makron Books, Coleção Schaum. São Paulo, SP, 643p. 1993.

SUDERHSA. Cadastro de usuários de recursos hidricos da regiāo metropolitana de Curitiba. Superintendência de Desenvolvimento dos Recursos Hídricos e Saneamento Ambiental. Curitiba, 1998.

USEPA. Review of draft technical guidance for biological criteria for streams and smal rivers. United States Environmental Protection Agency, EPA - SAB - EPEC - 94 - 003, Waschington D.C., 1993, 18p. 1993.

USEPA. Environmental indicators of water quality in the united states. EPA 841 - R - 96 - 002. United 
Bollmann, H. A. \& Edwiges, T.

States Environmental Protection Agency. Office of Waters., 26p. 1996.

WILHEM, J. L.; DORIS, T. C. Biological parameters for water quality criteria. Rev. Bioscience, vol.16, n. 6, p(477-481). 1968.

Endereço para correspondência:

Harry Alberto Bollmann Rua Imaculada Conceição, I I55

Bairro Prado Velho

802 I5-90 I - Curitiba - PR - Brasil

Tel.: (4 I)327 I- I 647

E-mail: harry.bollmann@pucpr.br 